\title{
ARGEL, SEGÚN EL DIARIO INÉDITO DE FRANCISCO XIMÉNEZ (1718-1720)
}

\author{
Por \\ HEDI OUESLATI
}

El interés por este historiador es muy reciente y constituye un importante descubrimiento historiográfico en el campo de la historia magrebi (1). Se trata de un historiador muy particular, que ha dejado un diario personal muy volumenoso que abarca casi 20 años de su vida en el Mágreb. En él se descubren muchas realidades históricas del siglo XVIII, contadas con espontaneidad y sin muchos prejuicios. El Dr. Míkel de Epalza le da el calificativo de cextractos de prensan, por ser un relato que trata de la vida cotidiana y un ureportajem vivo de la actualidad. En esta obra, el autor Padre Fray Francisco Ximénez muestra una gran capacidad de constancia y tenacidad, ya que escribió siete volúmenes del diario, prácticamente sin interrupción y dedicando a algunos días varias páginas de texto (2). La lectura de ese texto es fácil, agradable y no se hace pesada, gracias al estilo claro y vivo del autor.

Creo, pues, que el autor y su obra son sumamente representativos de una época interesante de la historia de Argelia (el siglo XVIII) y que su estudio vale la pena. Antes de analizar la obra, vamos a presentar brevemente a su autor, el Padre Francisco Ximénez.

(1) Francisco Ximenez fue descubierto por el biblífilo IGNACIO BAUER LANDAUER, publicando la obra resúmen «La Colonia Trinitaria de Túnezn (Tetuán, 1934). Luego aparecieron unos estudios parciales utilizando dicho libro:

- Robert Ricard, uDos puntos de la Colonia Trinitaria de Túnez, de Francisco Ximénezm. Al-Andalus (Madrid, 23, 1958 pp. $445-4521$

- M. Epalza, H. Queslati, «Observaciones de un Padre español de paso en Orán en la época de Mustafa Bushlaghim». Revue d'Histoire Maghrébine (Tunis, 12, 1798, pp. 191-201). En árabe.

- M. Epalza, aNouveaux documents sur les Andalous en Tunisie au début du XVIII s.», R. H. M. (Tunis, 17-18, 1980. pp. 79-1081.

- H. Queslati, «El Hospital Trinitario Español en Túnez: un documento de su archivo acerca del ataque argelino contra Túnez en 1556", R. H. M. Turis, 21-22, 1981, pp. 167-1761. En árabe.

2) El 1-7-1719, escribió Ximénez diez folios enteros (es decir, 20 páginas)

El 14-7-1719, cinco folios.

El 1-8-1719, once folios. 


\section{FRANCISCO XIMÉNEZ}

Los datos que poseemos sobre este autor son muy escasos, especialmente sobre el final de su vida, después de 1735, fecha de su salida definitiva de Túnez y su regreso a España, con lo que concluye el séptimo y último volúmen de su diario. La mayor parte de los datos biográficos serán sacados del diario mismo.

Nació Francisco Ximénez, hijo de Francisco Ximénez; el 2 de diciembre de 1685 en el pueblecito de Esquivias, a unos 40 kilómetros al sur de Madrid en dirección a Toledo (3). Tomó el hábito de la Orden Trinitaria en el convento de Dos Barrios cerca de Madrid, el 20 de abril de 1700 (4). Estudió en el convento de Toledo lógica y filosofía y pasó luego a la Universidad de Salamanca en 1704 para estudiar teología durante cuatro años (5). Se ordenó sacerdote en 1709, y le hicieron después Maestro de Novicios del convento de Toledo durante seis meses (6). Fue nombrado Predicador mayor del Convento de Cuéllar en 1710 y luego Vicario. En 1712, pasó a ser Predicador Mayor en Toledo (7). Demostró muchas veces su gran deseo de irse a Argel o a Orán para consolar y curar a los cautivos cristianos, y al final obtuvo el permiso de pasar a tierras argelinas, el 25 de junio de 1717. A partir de esta fecha, hace todas las diligencias para embarcar, pero no puede llegar a Orán hasta el 4 de mayo de 1718. Se quedó en esta ciudad sólo doce días, intentado en vano conseguir del Bey Mústafa Buchlaghem permiso para fundar allí un hospital (8). Dejó Orán y pasó a Argel el 21 de mayo de 1718. Alli entró al servicio del Hospital trinitario español, como Predicador Mayor, colaborando con el Padre Predicador Fray Francisco Navarro en la labor de decir misa y confesar a los cautivos.

Durante su estancia en Argel, Francisco Ximénez desplegó muchos esfuerzos para obtener del Bey de Argel Mohámed Ben Hasan el permiso para fundar un hospital en Orán. Cuando se dio cuenta que eso no era posible se dirigió a Túnez una primera vez, en enero de 1720, pero una tempestad le obligó a regresar a Argel (9). Finalmente embarcó el 19 de mayo de 1720, llegando a Túnez el 28 del mismo mes. Empezó a hacer diligencias para obtener del Bey Huséin Ben Ali el permiso para construir un hospital. Tampoco fue fácil esta empresa, pero a los dos años y medio de su llegada a Túnez, el 4 de agosto de 1722, ponía la primera piedra y el 23 de junio de 1723 abría sus puertas el Hospital trinitario de San Juan de Mata. El Padre Francisco Ximénez quedó como Administrador del Hospital hasta 1735 (10), cuando se marcha definitivamente a España (11). Aquí se agotan los documentos relacionados con su vida. Sólo el "Diccionario de los Escritores Trinitarios" (12) nos informa que en 1745, es decir a los sesenta años de edad, fue nombrado Ministro del convento de Tejada. Podemos suponer la fecha de su muerte se sitúa a los pocos años de este nombramiento.

Su obra escrita es inmensa y de gran valor histórico. Podemos citar los siete volúmenes de su Diario (13); una obra titulada "La Historia de Túnez» en nueve volúme-

3) El 2 de diciembre de 1721, escribió Ximénez en su diario: "Hoy por la tarde cumpli treinta y seis años". Ms. Biblioteca de la Real Academia de la Historia (BRAH), E. 196, p. 381.

(4) Ms. BRAH, E. 193. Todos los datos acerca de los primeros anos de la vida de Ximénez están en los folios $1 .{ }^{\circ}$ y 2 . $^{\circ}$ de este tomo del manuscrito.

(5) (6) (7) Jbíd.

(8) M. Epalza, H. Queslati, “Observaciones...”, op. cit. (1)

(9) F. Ximénez, "La Colonia Trinitaria de Túnez", op. cit., p. 176.

(10) Se señala sólo un corto viaje que habia efectuado a Espana en 1729, con la ocasión de la muerte de su padre.

(11) (12) Antonio de la Asunción, "Diccionario de escritores trinitariosm, Roma, 1898.

(13) Ms. BRAH, E. 193, hasta E. 199. 
es (14); una traducción del libro de Al-Wazir Al-Sarrâŷ: "Al-Hulal Al-Sundusiyya" (15); una traducción de "Al-Múnis" de Ibn Abî Dînâr (16). Además, dejo veinte volúmenes de "Anales de la Orden" (17) y una memoria acerca del convento trinitario de Teada (18).

Ahora sólo voy a exponer algunas de sus actividades y observaciones argelinas, extraídas de los dos primeros volúmenes de su diario argelino (por oposición al Diario Tunecinol (19). Abarca un período de dos años, desde 1718 a 1720.

\section{EL DIARIO ARGELINO DE FRANCISCO XIMÉNEZ}

\section{A) Sus actividades en Argel:}

Lo primero que llama la atención de la estancia de Ximénez en Argel, en abierto contraste con su actividad en Túnez, es que no sale casi nunca de la ciudad de Argel, excepto una vez en que visitó la ciudad de "La Belida".

Este viaje duró una semana del martes 9 al martes 16 de mayo de 1719 . El relato de este viaje ocupa once folios del Diario. El motivo de este viaje era el de visitar a los cautivos cristianos que se encontraban allí y exhortarles a la confesión. Le acompañaban en este viaje su habitual compañero Fray Teodoro Lázaro Sanz, un judío David que hablaba el árabe y un sirviente canario (20). Lo más interesante de este viaje es el relato que nos hace Francisco Ximénez del camino y de la gente. La primera impresión que expresa es la de la belleza del paisaje:

"Los jardines que dan recreación a la vista por la

abundancia de árboles frutales y silvestres que los

pueblan con tan deleitable amenidad" (21).

También le impresionaron:

«algunas casas de campo muy buenas de moros ricos» (22).

Y lo más pintoresco en este camino era el cuadro de la gente que vendían: «una leche agria y ácida, que llaman leben, de que usan mucho los moros» (23).

Pasó por BUFARIQUE (Bû Faría, a $35 \mathrm{Kms}$ de Argel):

"el cual es muy nombrado, por haber en él una feria

o mercado muy grande todos los lunes" (24).

Lo que más le asombró fue que:

"en todo el camino nadie nos hizo mal» (25).

(14) Ms. BRAH, E. 200, hasta E. 209.

(15) Ms. BRAH, E, $210=9 / 6.025$.

(16) Ms. BRAH, E. $200=9 / 6.015$.

(17) Están conservados en el Convento Trinitario de Toledo.

(18) Con la obra ya publicada por lg. Bauer Landauer, el conjunto de las obras de Ximénez serla de 33 volúmenes, lo que representa un excelente campo de investigación para postgraduación universitaria. Espero poder llevarlo a cabo yo mismo.

119) Para este estudio he utilizado los dos primeros tomos, es decir, los Mss. (E. 193v E. 194). Y aprovecho la ocasión para dar las gracias al doctor Míkel de Epalza quien me hizo fotocopiar dichos manuscritos.

(20) Un correligionario de Francisco Ximénez, Fray Teodoro Lázaro Sanz, fue su.compañero de viaje desde que salieron de Madrid hasta Argel, donde se puso enfermo. No pudo Fr. Teodoro pasar a Túnez y murió en Argel el 6 de junio de 1720 (F. Ximénez, "La Colonia Trinitaria...,

121 Ms. BRAH, E. 193, F. $110 \mathrm{v}$ hasta F. ${ }^{\circ} 121 \mathrm{r}$.

(22) hasta el (30) lbid. 
Nos describe luego la macería del Bey de Orán y la del Alcaide de Bufarique, de la cual:

"coge mucho vino"

y también mucha:

"manteca que se gasta mucho en esta tierra" (26).

Al llegar al Belida se aposenta en un "Fonduco". Empieza a describir la ciudad, cercada de una muralla y, según su parecer, con más de mil casas en total. Esas casas: "son muy buenas con tejados al estilo de España" (27)

porque:

"es tradición que le fundaron los moriscos que fueron

expulsados de Españan (28).

Le impresionan sobre todo las huertas que había alrededor de la ciudad con muchos árboles frutales, especialmente naranjos, limoneros, manzanos, viñas... Nota también que:

"los bastimientos son baratos» (29).

En efecto, parece que la vida era menos cara que en la capital, puesto que Ximénez no vino sólo a confesar a los cautivos, sino también:

"para comprar tablas para el Hospital, por haberlas

buenas y baratas en esta tierra» (30).

Así cumptió Ximénez con el doble cometido de su viaje, el religioso y el de la compra de las tablas, y se volvió a Argel.

En Argel, sus actividades se reducen a registrar los libros antiguos para enviar las noticias "más especiales" al Cronista de su Orden, visitar a los cautivos cristianos en los diversos baños de Argel y rezar responsos para los muertos cristianos enterrados en su cementerio de Babaluete (Bâb al-Wâd, Babeloued, fuera de la puerta norte de Argel). Algunas veces sale al campo a buscar hierbas medicinales, y en verano va de vez en cuando a bañarse a la playa. Sin embargo, pasa la mayor parte del tiempo mirando y analizando los más mínimos detalles de la vida diaria de la sociedad musulmana de Argel, que va anotando puntualmente.

\section{B) Observaciones de Ximénez sobre la vida argelina:}

No es posible, por supuesto, exponer todas las observaciones de Ximénez sobre la vida argelina, por muy interesantes que parezcan. Requeriría un libro entero (31). Pero vamos a intentar destacar aquí algunas de ellas.

1) La vida política:

Según el diario de Ximénez el gobierno de Argel es autoritairo y todo depende de la voluntad del Dey:

"aunque antiguamente se gobernaba Argel por un consejo

que había, a quien llamaban Duan Diwān),... hoy no le ha que-

dado más que el nombre, pues para castigar a moros,ju-

díos y cristianos sólo da la sentencia el Gobernador" (32).

(31) Estov reuniendo muchos datos de los tres volúmenes para poder publicar un librito sobre la sociedad argelina según el diario de Ximénez.

(32) Ms. BRAH, E. 193, F. ${ }^{\circ} 74 v, 27-2 \cdot 1719$. 
Se nota este despotismo en algunas órdenes caprichosas: "Hoy ha mandado Mahamet, Rey y Gobernador de Argel, que los cautivos cristianos no trabajen en nueve días, sino que se descansen... No se sabe que ningún otro Gobernador haya hecho otro semejante ejemplar en Argels (33).

El motivo de esta orden era el demostrar que todos los cautivos eran suyos $y$ que él mandaba lo que quería en ellos.

Sin embargo la imagen del Dey Mohamed Ben Hasan en el Diario de Ximénez no es del todo negativa. En muchas ocasiones recibió a Ximénez con mucha hospitalidad y simpatía. Notamos que en el Diario se repiten mucho las palabras "Rey" o "Gobernador" para designar al "Dey". También menciona muchas veces a su predecesor Baba Ali Chaouch y nos describe varias veces su sepulcro grandioso, en el centro de la ciudad (34). Advierte que murio de muerte natural, lo cual fue excepcional entre los Deyes de Argel, y que los argelinos lo consideraban como Santo y Morabuto.

Lo más espectacular de la vida política de Argel en aquella época era la entrada de los Beyes con el tributo (que Ximénez llama "Garraman). El Diario nos señala cada entrada con una descripción del ambiente y de la ceremonia. Da también la cantidad o valor de este tributo. Como ejemplo de comparación entre los diferentes Beyes, he aqui el valor del tributo de cada uno para el año de 1719:

- Entró el Bey de Titire el 20-4-1719 con siete cargas de monedas y siete cabaIfos (35).

- Entró el Bey de Levante el 27 de abril de 1719, con veinte y seis cargas de moneda, veinte caballos, un tigre y un león (36).

- Entró el Jalifa de Poniente el 18 de octubre de 1719 con treinta cargas de moneda y dieciocho caballos (37).

Sabiendo que cada carga trae dos mil pesos o dos mil patacas (38), se entiende que Ximénez califique à Argel como uno de los reinos más ricos del mundo (39).

Ximénez nos describe también la solemnidad de la elección de los Alcaides de partidas o aduares, al tercer día de cada Pascua de Corderos. Eran aquéllos de entre "aquellos moros ricos que le dan / at Rey / más dinero" (40).

Todos saben las dificultades que tuvo el Dey Mohamed Ben Hasan con las poblaciones autóctonas que se negaba a pagar los tributos. Ximenez nos describe este estado de rebeldía, sobre todo en la tierra del Cuco y en:

«otras montañas que están entre Orán y Argel, y estos

han obligado a los argelinos cuando pasan cerca de su

país, a llevar las banderas tendidas en tierra, en se-

ñal de que no van a conquistarios" (41).

Nos informa también que esta gente se gobernaba por sus propios jeques y vivian

(33) Ms. BRAH, E. 193, F. ${ }^{\circ} 79 r, 8-3-1719$.

(34) Ms. BRAH, E. 193, F. ${ }^{\circ} 17 r, F^{\circ} 19 r$, Ms. BRAH, E. 194, p. 203.

(35) Ms. BRAH, E. 193, F. ${ }^{\circ} 99 \mathrm{v}, 20-4-1719$.

(36) Ms. BRAH, E. 193, F. ${ }^{\circ}$ 105r, 27-4-1719.

(37) Ms. BRAH, E. 194, p. 182, 18-10-1719.

(38) Ibid.

(39) Ms, BRAH, E. 193, F. ${ }^{\circ} 81 r, 13-3-1719$

(40) Ms, BRAH, E. 194, p. 192, 26-10-1719.

(41) Ms. BRAH, E. 193, F. ${ }^{0} 50 \mathrm{v}, 17-1-1718$ 
en unas cuevas, y aunque reconocian la soberanía de Argel no pagaban tributo alguno (42).

En la política interior de Argel, nota que había una inspección regular de las tiendas de comercio por parte del "Cadín:

"al que halla que tiene las medidas y pesas faltas

le castigan (43).

Notamos, además, las numerosas sentencias contra los falseadores de moneda (44). Muchas veces castigaban a los panaderos, porque: "todos quitan mucho $y$ le hacen cortísimo" (45).

Hay varias maneras de castigar: la más utilizada era dar de palos. Pero habla otra descrita por Ximénez, y era meter al condenado desnudo en un costal a rodar para que los gatos arañen al condenado (era castigo reservado sobre todo para hacer reconocer el delito) (46).

\section{2) La sociedad argelina en el siglo XVIII:}

La sociedad argelina, según el Diario de Ximénez, era una típica sociedad de segregación, que se componía de diversos elementos étnicos viviendo bajo unas instituciones diferentes. Se pueden destacar cinco grandes grupos:

- Los Turcos: subdivididos entre ellos en "naturales" y "coloríos".

- Los Moros: que también se dividen en ciudadanos, rurales y montañosos, $y$ entre los originarios de Africa y los moriscos de origen español.

- Los Judíos: se dividen en originarios de Berbería y los nacidos en Europa.

- Los Cristianos: cautivos y libres (comerciantes, sacerdotes...) y gran número de renegados (convertidos al Islam) que servían en el ejército y en la marina corsaria.

- Los Negros: son esclavos de origen africano que servian en las casas y vivian marginados en la sociedad argelina.

Todos estos elementos se cruzan en el relato de Ximénez y forman el núcleo principal del interés del autor, que se pone a analizarlos en sus más importantes manifestaciones sociales, en la calle, en la mezquita, en las casas, en el puerto, en la escuela. en el hospital... Se puede revivir con sus "reportajes" aquella sociedad, empezando por las fiestas religiosas:

a) El Nacimiento de Mahoma:

"En esta fiesta blanquean y limpian muy bien las casas...

también ponen luces en muchas partes de las casas, $y$ ha-

cen navios, galeras y otras invenciones de cera para que

arde en este dia... También adornan con más especialidad las escuelas de los muchachos" (47).

Esto era el ambiente general de la fiesta del "Molut", que dura hasta nuestros días en las tradiciones magrebies. También Ximénez advierte que era un día de descanso para todos y que en él se comía aun buen Alcuzcuz".

\footnotetext{
(42) lbid.

(43) Ms. BRAH, E. 194, p. 152, 13-9-1719.

(44) El 18-2-1719, el 29-7-1719, el 13-2-1720.

(45) Ms. BRAH, E. 193, F. ${ }^{\circ} 62 \mathrm{v}, 13-2-1719$

(46) Ms. BRAH, E. 193, F. ${ }^{\circ} 69 \mathrm{~V}, 19-2-1719$.

(47) Ms. BRAH, E. 193, F. ${ }^{\circ} 54 \mathrm{v}, 2-2-1719$.
} 
b) La fiesta del Aïd:

Ximénez describe ampliamente esta fiesta que considera como la más importante de Argel, por la solemnidad con que se celebra:

"Por la calle había algunos moros con unos pomos de plata echando agua de color a todos los que pasaban, sin reservar a los cristianos... En algunas partes había algunos moros tocando un panderillo y una flauta de caña y pidiendo así limosna» (48).

Pero la gran feria se organizaba en Babaluete, donde había muchas diversiones sobre todo dedicadas a los muchachos y muchachas, para sacarles el dinero que les daban en aquel día sus padres. Entre estos juegos, Ximénez nos habla de columpios, de ruedas, de carritos upintados en forma de galeras»... También se oía música en todas partes y con instrumentos diferentes: gaita gallega, dulzainas, tambores...

c) La fiesta del carnero:

Ximénez da la cifra impresionante de 40.000 carneros que se habrían degollado en Argel durante la fiesta de noviembre de 1718:

"Todos van a la mezquita... y acabadas sus ceremonias, disparan la artillería, y el morabuto mata el carnero, y entonces hacen lo mismo todos en sus casas" (49).

En el palacio del Gobernador se daba a comer a toda la guardia, capitanes y principales soldados. También Ximénez y el Padre Administrador del hospital tenían que felicitar al Gobernador, asistiendo al espectáculo de luchas que presentaban los turcos. A Ximénez le regalan unos pasteles que llama "Macarotes":

"Que es una comida de masa, manteca, miel, y especie de frito, que tiene muy buen sabor" (50).

El tercer día de la fiesta estaba dedicado a la elección de los "Alcaides de Aduares", y Ximénez nos describe las diferentes festividades que acompañan a estas elecciones.

Estas son las principales manifestaciones de carácter religioso que celebran los argelinos. Pero hay también otras tradiciones:

a) La circuncisión:

Se advierte siempre en el Diario de Ximénez una gran emoción cuando describe una procesión de circuncisión, porque tiene mucho afecto a los niños argelinos. Varias veces dice que esos niños eran guapísimos y que por ellos podía adivinarse la hermosura de sus madres, ya que no podía contemplar directamente el rostro de las argelinas. Así nos describe una vez una procesión:

"Llevaban a circuncidar a un morillo. Le llevaba una negra en hombro, muy compuesto, con una berreta esmaltada de perlas, oro y mucha riqueza. Le acompañaban otros niños adornados de la misma forma..." (51).

A veces oía canciones, pero desgraciadamente Ximénez no comprendía el árabe $y$ no reproducía perfectamente voces como éstas:

(48) Ms. BRAH, E. 194, p. 124, 19-8-1719.

(49) Ms. BRAH, E. 193, F. $^{\circ} 27 r, 3-11-1718$.

(50) Ibid.

(51) Ms. BRAH, E. 193, F. ${ }^{\circ} 40 \mathrm{v}, 3-12-1718$. 
"Los muchachos que le acompañaban iban cantando:

Atteni Mahamet, Atteni Masapat» (52).

$Y$ según lo que le dijeron, esto quería decir: "Dadme Dios moros para circuncidarlos, o Dios de moros para ser circuncidos".

b) El entierro:

Ximénez es asombroso por la precisión con que describe las escenas de funerales. Tal la escena más curiosa es ésta de mujeres:

"Las viudas, hijas, parientas y amigas se juntan en la casa del difunto y hacen un óbalo redondo y todas puestas de pie. $Y$ una vieja... se sienta en medio, con un tamborillo... Entonces, con las uñas de las manos al son del tamborillo se arañan desde los sienes hasta la barba, desarrollándose de forma que se ponen carnecería, corriendo la sangre por las mejillas, especialmente la viuda. Y la más amiga se experimenta entonces en la que se araña mejor y sale más desfigurada... hasta que, cansadas y rendidas de arañarse, cantan gritando que se oye en lo más remoto de la ciudad" (53).

Ximénez nos señala que los argelinos consideraban como deber sagrado el ir acompañando al difunto hasta el cementerio. Y con su ironia y humor, nos dice que los ricos invitaban a los pobres para que les acompañasen y al final les daban limosna con pan e higos:

"Por la cual van muy contentos, y quisieran que cada

día hubiera muchos entierros para estar satisfechos": (54).

Nos describe cómo ponen el cuerpo mirando siempre al Oriente «donde está la casa de la Meca...", y como ponen semilla sobre la tumba "para que crezca y florezca». Al final ponían una tiendecilla para que viniese la viuda a visitar la tumba $y$ rezar para el alma de su difunto, llevando muchas cosas de comer para repartirlas entre los pobres.

Ximénez desarrolla también temas sobre el carácter mágico-espiritual de ciertas prácticas de la sociedad argelina, burlándose exageradamente de la ignorancia y de las hechicerías de los argelinos, especialmente de las mujeres, que vivían bajo el influjo de los morabutos y de los que llama "santos":

"No hay nación ninguna que tenga más santos que

los moros, así muertos como vivos" (55).

Y cita los nombres de los que se veneraban en aquel entoces: Sidi Dragman, Sidi Bennor, Sidi Abdelcader, Sidi Casi, Sidi Ysuf... En varias ocasiones, Ximénez nota que estos morabutos dominaban todas las instituciones, como:

a) La medicina:

"Los turcos y moros no entienden cosa alguna de

la medicina y cirujanía» (56).

(52) Ms. BRAH, E. 193, F. ${ }^{\circ} 76 r, 1-3-1719$.

(53) Ms. BRAH, E. 194, pp. 201, 202, 1-11-1719.

(54) Ibid.

(55) Ms. BRAH, E. 194, p. 45, 14-7-1719.

(56) Ms. BRAH, E. 193, F. ${ }^{\circ} 133 r, 10-6-1719$. 
Así advertía él la decadencia de la medicina en Argel: "Aunque antiguamente estudiaban estas facultades ya lo han olvidado todo... Sólo se valen en sus enfermedades de los morabutos que, con cédulas, nóminas y hechicerías intentan curar los enfermosw (57).

En otros lugares del Diario se descubre que en Argel se usaba mucho los cauterios $y$ Ximénez nota que se cauterizaba continuamente y en todas partes, dejando a veces el rostro horriblemente feo.

"También usan mucho el escribir / unos papeles/, los cuales les queman y hacen polvos, y con agua en diferentes días, se los dan a los enfermos...) (58).

Y se asombra Ximénez de que Argel, aunque era "una de las ciudades más ricas del orbe», no tenía un hospital:

«los que hoy entre los moros de Argel tienen nombre

de hospital son dos, los cuales están fuera de las murallas, uno junto a la puerta de Babazón, pero estos hospitales se reducen a... una choza de muy tenue fábrica, sin división de cuartos, sino sólo un portalillo, donde a algunos pobres se les da el cubierto" (59).

b) La educación y estudios:

"Los hijos de los moros, rara vez los dan las madres para que los crien otras personas, si no es que sea por necesidad muy grave de faltarles la leche...) (60).

Ximénez, con esta afirmación nos revela este sentimiento hasta hoy vigente en nuestra sociedad magrebi, a saber que la crianza de los niños es una responsabilidad exclusivamente a cargo de la madre. Luego, cuando llegaba el niño a la edad de seis o siete años, según dijo Ximẹnez, le llevaban a la escuela. Y muchas veces pasaba Ximénez por delante de las muchas escuelas que había en Argel. Se trata de las tradicionales escuelas coránicas, que estaban regularmente en un portalito y donde no cabían más que catorce o veinte alumnos. Los maestros y los alumnos se sentaban en el suelo:

"ninguno tiene ni lleva libro, sino unas tablas em-

barnizadas, de las cuales el maestro escribe la lec-

ción y la aprenden. Y en sabiéndola, borra aquélla $Y$ escribe otra» (61).

Y con su habitual ironía nos dice que al saber el muchacho leer y escribir, "ya está graduado de muy sabio», porque decía que no estudiaban más que esto. Los alumnos se llamaban "Tolbas» y tenían el privilegio de tener derecho a un pedazo de pan diariamente cada uno de un hornero:

"Y si compran algún pan más barato que a los demás, de suerte que vendiendo cada pan a los demás en cinco ásperos, a elios se le dan a dos» (62).

\footnotetext{
(57) Ibid.

(58) ibid.

(59) Ms. BRAH, E. 194, p. 142, 1-9-1719.

(60) Ms. BRAH, E. 194, p. 220, 1-12-1719.

(61) Ms. BRAH, E. 194, p. 230, 1-12-1119.

(62) Ibid.
} 
$Y$ en las horas libres, se iban pidiendo limosnas para mantenerse.

Por otra parte, Ximénez descubre un curiosísimo fenómeno cultural, que era el esfuerzo de arabización de los "Cabayles" del Cuco (Kûkû, entonces capital de las cábilas o tribus berberoparlantes de la región de Djurdjura o Gran Cabitia, a unos 160 $\mathrm{kms}$. de Argell. Según Ximénez, un poderoso turco Alí Jochá fundó allí un castillo muy bien guarnecido, en 1711:

"Tiene el dicho Alcaide a las faldas y contorno del dicho castillo algunas escuelas, donde tiene puestos sus maestros para que enseñen a los morillos de diez o doce años, manteniéndolos todos a su costan (63).

b) Las diversiones de los argelinos:

Para pasar su tiempo libre, los argelinos - según el Diario de Ximénez - practicaban muchos deportes, como la lucha, o jugaban a la "pina": "con una bola y un palo cada uno, unos a darla $y$ otros a estorbarn (64).

Sin embargo, por ser Argel una ciudad-puerto, el lugar que tenía más atracción eran las tabernas, muy numerosas en los baños, aunque los clientes eran sobre todo los turcos, que en aquellas tabernas "tienen muy buenas músicas de diferentes instrumentos con que se divierten y pasan alegremente los días" (65).

Pero en aquellas tabernas no sólo había vino y música, sino también sexo, porque: "lievaban alli muchachos por sus bestiales apetitos" (66).

Ximénez está horrorizado de lo que llamaba «bestialidades de los Turcos», y dice: "No sé como a esta tierra no la brasa Dios como a las ciudades de Sodoma y Gomorha, por las muchas $y$ frecuentes sodomias $y$ bestialidades que se cometen" (67).

Ximénez nos da la cifra asombrosa de que había en Argel en su época más de trece mil-(13.000) "malas mujeres" que andaban por las calles: "cubiertas con un velo y descubriendo el rostro cuando les parece, y con unos calzoncillos, solicitando torpemente a los hombres" (68).

Estas mujeres trabajaban bajo una legislación especial y las defendía un verdugo que Ximénez llama "El Mesuar", que además cobraba de ellas el tributo que tenían que pagar ai Rey. Cada una pagaba según la edad y hermosura que tenía:

"La que menos paga seis reales de plata cada luna.

otras un real de a ocho, $y$ las hay a tres o

cuatro pesos" (69).

\footnotetext{
(63) MS. BRAH, E. 193, F. 48r, 16-1-1719.

(64) Ms. BRAH, E. 193, F. ${ }^{\circ} 64 v, 16-2-1719$.

(65) Ms. BAAH, E. 193, F. ${ }^{\circ} 70 \mathrm{v}, 21-2-1719$.

(66) Ibid.

(67) Ms. BRAH, E. 193, F. $34 r, 14-10-1718$.

(68) Ms. BRAH, E. 194, p. 94, 1-8-1719.

(69) Ibid.
} 


\section{LA VIDA CORSARIA:}

Argel era, en tiempo de Ximénez, un gran centro marítimo, en el que se refugiaban gran número de piratas, aunque eran menos que en el siglo XVI. Diego de Haedo, en 1581, había enumerado 35 bajeles de Corso, mientras que en tiempos de Ximénez: "son catorce los vajeles corsarios que hay en Argel con que hacen notable daño a la Cristiandad” (70).

En el Diario aparecen frecuentemente los nombres de los más famosos corsarios de aquel tiempo. Viquer Arraez, Benabdi, Negro, Chulaque, Sidi Catre, Babazán, Caramacachi, Bocandora, Tabacquo... Y si el número de los bajeles era menor que en la época de Haedo, es cierto que el tamaño era más importante y la técnica más perfeccionada, como en el caso del bajel de Baylique que salió por primera vez el 15 de junio de 1719 y que llevaba cincuenta y seis cañones y ochocientas personas (71).

Ximénez menciona a un gran corsario que vivió a finales del siglo XVII y que llama El Gran Canario, que llegó a ser tan rico que fabricó en Argel in gran palacio, que era uno de los mejores de la ciudad. Allí vivía, en tiempos de Ximénez, el cónsul de Inglaterra. También señala Ximénez que los corsarios sólo salian a corso el jueves o el lunes, por ser días de buen agüero.

\section{PERSONALIDADES IMPORTANTES:}

Ximénez se encontró en Argel con muchas personas influyentes y famosas, entre las cuales se pueden destacar las siguientes:

1) El Guardián Bassi: era un renegado (convertido al Islam) de origen maltés, que tenía mucha autoridad. Los españoles del hospital se servian de su influencia para que interviniese a veces acerca del Bey:

"Se dieron hoy al Guardián Bassi cuarenta doblones

por haber sacado la licencia del Gobernador para hacer la enfermería" (72).

2) Mostafá Benamar: era un morisco "tagarino", el más rico de todo el reino de Argel, propietario del mayor número de esclavos entre los particulares, con más de cien cautivos:

\section{"preguntando Achi Mostafa Benamar a unos cautivos} españoles, qué hacienda tendría un Grande de España, le respondieron que seis o siete millones.

A esto dijo: pues, yo también pudiera ser Grande de España, que mi caudal aún es más que eso.... (73).

Además, nos señala que el 23 de mayo de 1719 había muerto Benamar el Topal, otro morisco tagarino "de los más ricos del reino". Con esto se nota la gran influencia de los moriscos en la sociedad argelina del siglo XVIII. Parece que eran numerosos, porque una vez murió uno de ellos:

"maestro de obras tagarino, y asistieron al entierro

más de quinientos tagarinos" (74).

(70) Ms. BRAH, E. 193, F. ${ }^{\circ} 91 r, 3-4-1719$.

(71) Ms. BRAH, E. 193, F. ${ }^{\circ} 136 r, 15-6-1719$.

(72) Ms. BRAH, E. 193, F ${ }^{\circ} 91 \mathrm{v}, 4-4-1719$.

(73) Ms. BRAH, E. 194, p. 136, 1-9-1719.

(74) MS. BRAH, E. 194, p. 341, 14-2-1720. 
Este oficio de maestro de obras parece ser una especialidad de los moriscos, por que también el maestro que construyó la enfermería del hospital trinitario se llamaba «Sidi Ali» y era tagarino.

3) Don Bartolomé Arani: es el ingeniero de la obra de Baylique, muy poderoso: "Los cristianos no lo pueden ver, ni aún los moros ni turcos, por el dominio que se toma..." (75).

purque les hacía trabajar "más de lo que alcanzan sus fuerzas». Fue él el que construyó el castillo de la Marina e intentó hacer minas para sacar plata, un asunto que le salió muy mal y en el que arriesgó su propia vida.

También en el diario se repiten los nombres de los cónsules inglés y francés (al que Ximénez llama Monsiu Bato), de los Truchimanes (sobre todo el truchimán francés Ebraín Jocha "que es moro muy fino»), etc.

\section{EL CAMPO ARGELINO:}

Ximénez era un gran admirador del campo argelino y le gustaba salir a veces a dar un paseo fuera de las murallas de la ciudad. El 24 de enero escribe sus impresiones después de un paseo:

"Es admiración ver lo florido que está el campo: los rosales llenos de rosas, las lechugas muy crecidas, rábanos, zanahorias, unos carditos hay muy pequeños que son alcachofas... Hay acelgas, navos, espinacas... Hay cebollas y ajos. Y de legumbres hay garbanzos, judías, habas, trigo, cebada, lentejas... Hay también melones, sandías, calabazas de diversos géneros y muy lindos, berenjenas...॥ (76).

Y Ximénez varias veces alaba la fruta principal que había en Argel, que era el albaricoque.

\section{CONCLUSIONES:}

Esta obra del Padre Francisco Ximénez puede ser fuente importante para la historia de Argelia, ya que es un testimonio bastante objetivo de la sociedad argelina en una época aún mal conocida. En esta obra se señalan diversos elementos de la sociedad argelina, descritos por el Diario de Ximénez, que es un documento de género literario muy interesante, ya que los datos históricos y sociológicos no están descritos con intención de hacer una historia erúdita. Así Ximénez, en el prólogo del segundo volúmen pone de manifiesto esta idea, diciendo:

«El principal asunto de esta obra es referir diariamente los sucesos más notables de esta ciudad... Cosas que pasan por mis ojos, $v$ otras que me refieren los cautivos: (77).

Es exactamente como si fuera corresponsal de periódico, un trabajo de observación y de apuntes, a veces sin comentario, con un estilo espontáneo y directo: "No me valgo de frases cultas sino de estilo claro

(75) Ms. BRAH, E. 193, F. ${ }^{\circ}$ 140r, 20-6-1719

(76) MS. BRAH, E. 193, F. ${ }^{\circ} 52 \mathrm{v}, 24-1-1719$.

(77) Ms. BRAH, E. 194, Prólogo. 
y llano como me le ha dado la Naturaleza, sin poner especial cuidado en el estilo, sino declarar lisamente los sucesos" (78).

Pero no hay que olvidar que Ximénez era ante todo un Religioso cristiano que se encontraba en una tierra hostil a su país y a su Religión, donde veía a millares de sus correligionarios sufriendo el inhumano estado de cautiverio. Todo le impresiona en esta situación: la gente, las instituciones, los comportamientos. Pero no podía comentar nada ni discutir con nadie. $Y$ así nació el Diario como forma de desahogo y de exteriorización y como una forma de esa comunicación que le faltaba a Ximénez en Argel. Tres grandes volúmenes para relatar los hechos de dos años de la historia de Argelia tal y como la vio son una referencia importante.

Espero que este pequeño y modesto trabajo-resumen haya hecho descubrir esta fuente española para la Historia de Argelia y hava supuesto un paso adelante para conocer mejor el siglo XVIII argelino.

(Trabajo presentado en el Seminario Internacional sobre las Fuentes Españolas de la Historia Argelina. Orán: 20-22 de abril de 19811. 